\title{
Wave after wave - Determining the temporal lag in Covid-19 infections and deaths using spatial panel data from Germany
}

Manuela Katharina Fritz ( $\sim$ manuela.fritz@uni-passau.de)

University of Passau: Universitat Passau https://orcid.org/0000-0002-6507-644X

\section{Research Article}

Keywords:

Posted Date: May 3rd, 2022

DOI: https://doi.org/10.21203/rs.3.rs-447920/v2

License: (c) (1) This work is licensed under a Creative Commons Attribution 4.0 International License.

Read Full License 


\begin{abstract}
The Covid-19 pandemic requires a continuous evaluation of whether current policies and measures taken are sufficient to protect vulnerable populations. One quantitative indicator of policy effectiveness and pandemic severity is the case fatality ratio, which relies on the lagged number of infections relative to current deaths. The appropriate length of the time lag to be used, however, is heavily debated. In this article, I contribute to this debate by determining the temporal lag between the number of infections and deaths using daily panel data from Germany's 16 federal states. To account for the dynamic spatial spread of the virus, I rely on different spatial econometric models that allow not only to consider the infections in a given state but also spillover effects through infections in neighboring federal states. My results suggest that a wave of infections within a given state is followed by increasing death rates 12 days later. Yet, if the number of infections in other states rises, the number of death cases within that given state subsequently decreases. The results of this article contribute to the better understanding of the dynamic spatio-temporal spread of the virus in Germany, which is indispensable for the design of effective policy responses.
\end{abstract}




\section{Introduction}

By the end of 2019, a novel coronavirus, the severe acute respiratory syndrome coronavirus 2 , in short Covid-19, was detected in the city of Wuhan in China (Guan et al., 2020; Zhang et al., 2020). What seemed first to cause only a country wide epidemic has fast developed into a worldwide pandemic, which is by now judged as the greatest human challenge since the Second World War. By the time of October 2021, the pandemic has caused about 246 million infections and more than 4.9 million deaths worldwide.

As a policy response, several countries implemented severe lockdowns, including school and store closings, curfews and travel bans to reduce human interaction and thereby the spread of the virus. While aiming to save human life, such restrictions also limit human freedoms. Hence, they require a continuous evaluation of whether they are sufficient to protect vulnerable populations and whether more or less strict measures can and should be considered. One quantitative indicator of policy effectiveness and pandemic severity is the case fatality ratio (WHO, 2020; Ioannidis, 2021), which is based on the current number of deaths relative to the lagged number of infections. The appropriate length of the time lag to be used, however, is heavily debated (Baud et al., 2020; Kim and Goel, 2020). An accurate measure is essential as both, over and underestimation can have severe consequences, such as not taking the pandemic seriously or causing redundant panic (Kim and Goel, 2020).

The literature reflects the uncertainty about the appropriate length. Chrusciel and Szybka (2021), for example, investigate the time lag in several European countries and find that the lag between reported cases and deaths averages around seven days. Vanella et al. (2020) also investigate the appropriate time lag for European countries to calculate an unbiased case fatality ratio and conclude that a lag between five and ten days should be used. Testa et al. (2020) determine the lag for US counties and find a substantially longer lag. They conclude that deaths often occur two to eight weeks after the onset of the first symptoms. Wilson et al. (2020) determine the case fatality ratio for China and find that a 13-day lag best describes the pattern of the data.

To add to this debate, I provide rigorous evidence for the length of the time lag between a rise in infections and a subsequent rise in death cases using daily panel data for Germany's 16 federal states 
from May 2020 to December 2020. In comparison to the studies outlined above, however, I rely on a

spatial econometric approach to consider the dynamic spatial spread of the virus. I thereby also add to the literature that analyses the spatial dynamics of Covid-19 and quantifies the spatio-temporal interactions and spillovers of the virus (e.g., Guliyev, 2020; Krisztin et al., 2020; Ehlert, 2021). Specifically, I estimate different spatial econometric models that allow not only to consider the infections in a given state but also those in neighboring states, so-called spatial lags. Spatial econometric models are useful to model interaction effects between geographical units (Elhorst, 2021) and are hence especially useful to model the global-spreading and infectious nature of the coronavirus.

I determine the lag between the wave of infections and the wave of Covid-19 casualties in Germany's federal states and their geographical spread with four spatial models: I use (1) a model with spatial lags in the independent variables (SLX model), (2) a non-dynamic and (3) a dynamic model that include spatial lags in both, the dependent and independent variable, together with space and time fixed-effects (Spatial Durbin Models with fixed-effects), and (4) a dynamic Spatial Durbin Model with common factors to capture potential strong cross-sectional dependence (i.e., cross-sectional averages instead of time fixed-effects). All of these spatial models allow to derive the direct (same-state) and indirect (other states) effects of infections on death cases. Specifically, the direct effect shows the marginal effect on the number of death cases driven by a change in the number of infections in the own state, while the indirect effect is the marginal effect on the number of death cases driven by an increase in infections in all other states, while both effects taken together form the total effect (Golgher and Voss, 2016).

All four spatial econometric models have the advantage that the spillover effects are fully flexible, i.e., they can take any value, which makes them more suitable for economic research focusing on spillover effects in comparison to a Spatial Autoregressive Model (SAR) or Spatial Autoregressive Combined Model (SAC) (Elhorst, 2021). Moreover, the two dynamic models allow to differentiate between shortrun (SR) and long-run (LR) effects, i.e. is possible to assess whether the effect of an increase in infections on the number of death cases fades out over time, if, for example, effective policies are implemented to protect the most vulnerable. 
The remainder of this article proceeds as follows. In Section 2, I present the data used for the analysis. In Section 3, I outline the empirical strategy and briefly discuss the differences in the spatial econometric models. I present the results in Section 4 and conclude in Section 5.

\section{Data}

\section{Daily infections and daily death cases}

The main variables used in this article are the number of daily new infections and the number of daily reported death cases due to Covid-19 in Germany at the federal state level. There are in total 16 federal states and the German Robert Koch Institut (RKI) provides and updates the respective numbers on a daily basis since the very beginning of the pandemic. ${ }^{1}$ Yet, as the number of cases in the first and second wave are not directly comparable (due to different testing strategies and measures taken), I make use of the data from the period between May 1, 2020 to December 31, 2020, hence dropping observations from the first wave's peak as well as those that were recorded after the vaccination campaign started. The latter is done to get an estimate of the time lag between infections and deaths without the vaccine being available, hence, an unbiased measure of when the rise of deaths should be expected after a rise of infections.

\section{Population and geospatial data}

To make the numbers of infections and deaths comparable across the different states, I calculate them per 100,000 inhabitants in the respective state. The corresponding population numbers are derived from the Bundesamt für Kartographie und Geodäsie ${ }^{2}$ which provides geospatial shape files for Germany, including population numbers for each state. The same source is used to derive the geographical coordinates for each state, which are essential to construct the spatial weight matrix used in spatial models (see Section 3).

\footnotetext{
${ }^{1}$ https://www.rki.de/DE/Content/InfAZ/N/Neuartiges_Coronavirus/Fallzahlen.html.

${ }^{2}$ See http://sg.geodatenzentrum.de/web_download/vg/vg250_0101/vg250_0101.pdf for a description of the data set.
} 


\section{Intensive care cases}

To be able to derive an unbiased estimate of the time lag between infections and death cases, I control for the number of daily new intensive care (IC) cases per federal state, i.e., the number of patients that have contracted the corona disease and are under intensive care. This variable is also calculated per 100,000 inhabitants. The number of daily new IC cases might be positively related to both variables of interest, the number of infections and deaths. Hence, including the variable in the regression avoids an upward omitted variable bias. Information on the number of patients in IC is provided by the RKI and the German Interdisciplinary Group for Intensive and Emergency Care (DIVI). ${ }^{3}$ The data are available on a daily level and per federal state.

\section{Temperature data}

The medical literature reports that respiratory diseases and infections follow seasonal cycles and are susceptible to temperature (e.g., Shaman et al., 2010; Martinez, 2018). Similar patterns have recently been confirmed for the coronavirus. Ma et al. (2020), in their analysis on temperature and humidity effects on Covid-19 deaths in China, find that higher temperatures lead to increases in death cases. Wu et al. (2020) contrarily identify a negative relationship between temperature and new cases and deaths in a study on 166 countries. To control for the potential confounding factor of temperature, I include the daily mean temperature on the state level in my analysis. Data on daily meteorological conditions is received from the German Weather Service (DWD). The DWD provides daily time series data for 538 weather stations across Germany, including the coordinates of each station. I merge each station to the corresponding federal state, using their respective coordinates, and average the mean temperature across all stations.

Figure 1 shows the spatial distribution of the number of infections per 100,000 inhabitants per state cumulated over the observation window from May 1, 2020 to December 31, 2020. The figure shows a clear variation in the number of cumulative Covid-19 cases across all federal states, with states in the south and south-west being the most severely affected. From a first glimpse, cross-sectional dependence seems to be present as there is some clustering of states with similar infection rates.

\footnotetext{
${ }^{3}$ https://www.intensivregister.de/\#/index.
} 


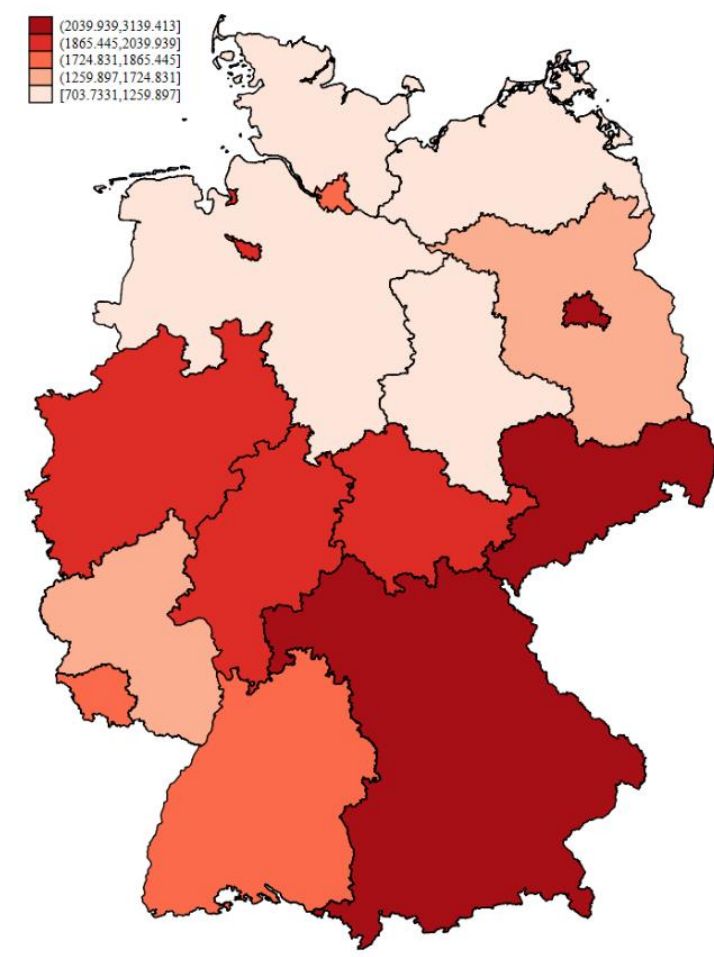

Figure 1: Cumulative Covid-19 infections in Germany. Notes: The map shows the cumulative number of Covid-19 infections per 100,000 inhabitants between May 1, 2020 and December 31, 2020 for the 16 federal states in Germany.

To confirm the presence of cross-sectional dependence statistically, I use Pesarans's CD-test for panel data (Pesaran, 2004, 2015), which is based on the pairwise correlation coefficients of the different geographical units. I also estimate the standardized cross-sectional exponent $\alpha$ (Bailey et al., 2016) to determine the degree of cross-sectional dependence. The results are shown in Table 1 and confirm the cross-sectional dependence for the number of infections. Cross-sectional dependence is also confirmed for deaths, the number of IC patients and temperature. The correlation is in each case significant at the $1 \%$ level and very strong as the exponent $\alpha$ of nearly one indicates. This suggest that a model with common factors instead of time fixed-effects might be better suited to capture the strong cross-sectional dependence (Ciccarelli and Elhorst, 2018; Elhorst et al., 2021). Proxying for common factors can be empirically implemented by either cross-sectional averages (pioneered by Pesaran, 2006) or principle components (e.g., Bai, 2009; Shi and Lee, 2017; Bai and Li, 2021); the former approach following Peseran (2006) is applied in this study. 
Table 1: Pesaran's CD test for cross-sectional dependence and Bailey et al.'s cross-

\section{Empirical Strategy}

To identify the time lag between the number of cases and the number of deaths, I rely on a spatial econometric approach, which allows me to model direct effects within the geographical unit of interest, while accounting for possible interaction effects with neighboring spatial units. Elhorst (2021) differentiates between three types of interactions: (1) exogenous interactions effects (i.e., the independent variable in one spatial unit can affect the dependent variable in other spatial units), (2) endogenous interaction effects (i.e., the dependent variable in one spatial unit can affect the dependent variable in other spatial units), and (3) interaction effects among the error terms (i.e., the error term in one unit can affect the error term in other units). In the modeling approach outlined below, I consider endogenous and exogenous interaction effects.

I use the number of daily deaths per 100,000 inhabitants within each state as dependent variable and regress it on the same-day number of new infections per 100,000 inhabitants in the same state as well as on the number of new infections per 100,000 inhabitants up to 14 days lagged in time in the same state. As explained above, I do control for the number of new patients with the Corona-disease per 100,000 being treated in IC as well as for mean temperature. Both variables also enter the regression with in total 14 time lags. Moreover, I include state fixed-effects to control for all non-time-varying effects that are specific to each state (such as being located at the sea or at the border to a different country) and which might impact the number of daily death cases and infections. Also, day fixed-effects are included to control for time effects affecting all states similarly. This will, for example, control for the effect of the whole country being in lockdown as well as for week-day specific patterns, such as fewer tests during the weekend. 
So far, this model corresponds to a 'standard' distributed lag model with fixed-effects. To account for the spatial dependence, I further add the spatial components to the model. The full model reads

$$
\begin{array}{r}
\text { Deaths }_{i t}=\text { tDeaths }_{i t-1}+\rho \sum_{j=1}^{N} w_{i j} \text { Deaths }_{j t}+\eta \sum_{j=1}^{N} w_{i j} \text { Deaths }_{j t-1}+ \\
\sum_{k=0}^{14} \beta_{k} \text { Infections }_{i t-k}+\sum_{k=0}^{14} \theta_{1 k} \sum_{j=1}^{N} w_{i j} \text { Infections }_{j t-k}+\sum_{k=0}^{14} \delta_{k} \text { Temperature }_{i t-k}+ \\
\sum_{k=0}^{14} \theta_{2 k} \sum_{j=1}^{N} w_{i j} \text { Temperature }_{j t-k}+\sum_{k=0}^{14} \gamma_{k} \text { Intensive }_{i t-k}+ \\
\sum_{k=0}^{14} \theta_{3 k} \sum_{j=1}^{N} w_{i j} \text { Intensive }_{j t-k}+\alpha_{i}+\sigma_{t}+u_{i t}
\end{array}
$$

where $w_{i j}$ are the elements of the matrix $\boldsymbol{W}$, which is a $16 \times 16$ row-normalized binary contiguity matrix, with its elements being equal to one when state $i$ and state $j$ are neighboring states and zero otherwise, and all diagonal elements $w_{i j}$ with $i=j$ equal to zero. ${ }^{4} \alpha_{i}$ and $\sigma_{t}$ are the federal state and time fixedeffects, respectively, i.e. a binary dummy variable is included for each state $i$ and each day $t$ (minus one to avoid the dummy variable trap). Deaths it $_{\text {Infections }}$ it and Intensive $i t$ are the respective numbers of death cases, infections and intensive care patients per 100,000 inhabitants at day $t$ in state $i$. Temperature $_{i t}$ is the mean temperature at day $t$ in state $i$. The subscript $j$ always denotes all states excluding state $i . u_{i t}$ is the error term. $k$ is an index running from 0 to 14 and indicates the respective time lag.

I estimate five different specifications of the outlined model by constraining several of the parameters. In Model (1), I set $\tau=\eta=\rho=\theta_{1 k}=\theta_{2 k}=\theta_{3 k}=0$, resulting in a standard distributed lag model with spatial and time fixed-effects. With these restrictions, no spatial spillover effects can occur.

In Model (2), I set $\tau=\eta=\rho=0$, such that the model is the SLX model (spatial lag in independent variables). This model allows only to derive long-run and only local spillover effects, i.e., spatial effects cannot change in size over time and only neighboring states can affect each other - which is, however, an implausible assumption given the global spread of the virus.

\footnotetext{
${ }^{4} \boldsymbol{W}$ can also be defined as inverse distance matrix, where the elements $w_{i j}$ are the inverse of the distance between state $i$ and state $j$. I also estimated all models using an inverse distance matrix, but this specification performed statistically worse in every model.
} 
In Model (3), therefore, I allow $\rho$ to be different from 0 and thereby for global spillover effects. I only

set $\tau=\eta=0$, leading to static Spatial Durbin Model with fixed-effects. Finding the parameter $\rho$ to be significantly different from zero implies global spillover effects, since also non-neighboring states can (through other states) affect each other. The static model, however, does not allow to differentiate between short-run and long-run effects, i.e. does not allow to investigate whether the effects become smaller or larger over time.

Allowing all parameters to differ from zero results in Model (4), the dynamic Spatial Durbin Model with spatial and time fixed effects. As outlined above, adding the dynamic element allows also to differentiate between short-run and long-run effects, i.e. to assess whether the effect size and significance changes over time or remains constant. In Model (5), I drop the time fixed-effects and instead account for common factors by including the cross-sectional averages (following Pesaran, 2006) for

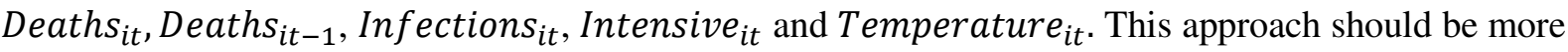
suitable to account for the strong cross-sectional dependence that was indicated by the high crosssectional exponent $\alpha$.

The parameters of the model in equation (1) are estimated via Ordinary Least Squares (OLS) if no endogenous interaction effects are included (i.e. in Model (1) and (2)), and by (quasi) maximum likelihood if endogenous interaction effects are considered (Model (3)-(5)), since estimating spatial models with endogenous interaction effects via OLS will result in inefficient estimates (LeSage and Pace, 2009). The bias correction approach of Yu et al. (2008) is applied in the two dynamic models to yield centered confidence intervals (see also Lee and $\mathrm{Yu}, 2010$ ).

One drawback of the bias-corrected QML estimator is that it will be inconsistent under heteroskedasticity (Bai and Li, 2021). Standard errors for all models are therefore adjusted for possible heteroskedasticity by applying the robust standard error approach proposed by Driscoll and Kraay (1998) (see also Hoechle, 2007, and Belotti et al., 2017). ${ }^{5}$

\footnotetext{
${ }^{5}$ Other quasi-maximum likelihood estimators for dynamic spatial panel data models with common factors that are consistent in the presence of heteroskedasticity have been proposed (see Bai and Li, 2021). Yet, this estimator has not yet been studied for models that also include the spatio-temporal lag of the dependent variable, i.e. the variable $\sum_{j=1}^{N} w_{i j}$ Death $_{j t-1}$ in the model of equation (1). Moreover, until now there exists no routine that would allow to
} 
The parameters $\eta, \rho, \theta_{1 k}, \theta_{2 k}$ and $\theta_{3 k}$ jointly determine the spatial interaction effects. The main parameters of interest to determine the time lag are the parameters $\beta_{k}$ and $\theta_{1 k}$. However, the point estimates cannot directly be interpreted as the direct effects and the spillover effects (except in the SLX model), but have to be calculated separately. Specifically, as soon as endogenous interaction effects enter the regression, the direct effect is calculated as the mean diagonal element of the models' $\mathrm{N} \times \mathrm{N}$ matrix of partial derivatives $((1-\tau) \mathbf{I}-(\rho+\eta) \mathbf{W})^{-1}\left[\beta_{\mathrm{k}} \mathbf{I}+\mathbf{W} \theta_{\mathrm{k}}\right]$, where $\mathbf{I}$ is the identity matrix. The indirect effect is the mean row sum of the non-diagonal elements of the same matrix (LeSage and Pace, 2009; Debarsy et al., 2012; Elhorst, 2014; Elhorst, 2021). To differentiate between the short- and long-run effects, the respective parameters $\tau$ and $\eta$ have to be set equal to zero. ${ }^{6}$ The corresponding standard errors are computed via Monte Carlo simulations (LeSage and Pace, 2009). A complete and detailed overview for the formulas of the marginal effects (for short- and long-run direct and indirect effects) as well as for the respective t-values or standard errors can be found in Elhorst (2014, page 25 and 105) and in Belotti et al. (2017, page 146).

\section{Results}

Table 2 presents the regression coefficients for each of the models outlined above, while Table 3 presents the corresponding (short-run and long-run) marginal direct effects and spillover effects.

Column (1) in Table 2 displays the results for the standard linear distributed lag model with fixed-effects, in which the point estimates of the parameters can be interpreted directly. It shows, as expected, that the number of daily infections is a strong determinant of the number of deaths cases. An interesting pattern can be observed: the number of the same day infections positively relates to the same day number of deaths cases, while the first lag is negative. This suggests that some form of mortality displacement is present, i.e., a temporary increase in death cases is followed by days with decreased death cases. While this phenomenon has especially been observed during heat waves (see for example Deschênes and Moretti, 2009; Karlsson and Ziehbart, 2018), studies also investigate this phenomenon in the context of

implement this estimator in Stata. Developing Stata routines to allow the application of this heteroskedasticityrobust estimator would be of great value for future research.

${ }^{6}$ In the static Spatial Durbin Model, the parameters $\tau$ and $\eta$ are zero by construction, but the resulting marginal effects are interpreted as long-run marginal effects. 
Covid-19 (Michelozzi et al., 2020; Cerqua et al., 2021). Afterwards, the effects become again

significantly positive at lag eight, followed once by negative effects at nine and ten days lagged, and then turning once again positive and significant at lag 11 to 14 . Hence, this first basic model suggests that the number of Covid-19 death cases consistently rises after an increase in number of infections after about 11 days. The coefficients for the daily mean temperature are insignificant, while the coefficients for the intensive care variable are first partly negative and become positive after about one week (coefficients for temperature and intensive care cases are shown in Table A1 in the Appendix). This model, however, does not yet account for spatial interdependence, reflected also in the value of the CDtest for the residuals. It shows that the test statistic does not lie within the interval $[-1.96 ; 1.96]$, which is needed to conclude that there is no further cross-sectional dependence in the residuals. At this point it is to mention that the CD-test significantly loses in power as soon as time fixed-effects or common factors are included in a model. Nevertheless, it is used in empirical studies to decide on model fit (see for example Halleck Vega and Elhorst, 2016; Ciccarelli and Elhorst, 2018), but should always be interpreted carefully and only be considered jointly with other test statistics, namely R-squared, the loglikelihood, and the cross-sectional exponent $\alpha$. The latter supports the rejection of the model as it is not significantly different from 1 .

Moving to the SLX model in Column (2) already improves the model fit as the increased values of Rsquared and the log-likelihood indicate. It also allows to make a first statement about local spillovers. They show that the number of infections in neighboring states $j$ also significantly relates to the death cases in state $i$, yet the coefficients are primarily significantly negative, and only turn positive after a lag of eleven days. Specifically, the spillover effects suggest that an increase in infections in neighboring states leads first to a decrease in own-state death cases with a three to ten-day lag and afterwards to an increase in own-state death cases with an eleven to 13-day lag. In terms of the size, an increase in infections of 1,000 per 100,000 inhabitants within a given federal state would lead to about five to six more deaths after 12 to 13 days, while an increase in infections of 1,000 per 100,000 inhabitants in neighboring federal states would lead to one to two more deaths after eleven to 13 days. As before, the direct and indirect effects for temperature are insignificant and those for the intensive care patients support the positive effect after about one week (shown in Table A2 in the Appendix). The residual CD- 
test statistic jointly with the cross-sectional exponent $\alpha$ being indifferent from 1 , however, do again not

allow to conclude that this model well captures fully the cross-sectional dependence.

Column (3) displays the results for the non-dynamic SDM with fixed effects, which includes now also an endogenous interaction effect. The coefficient $\rho$ is significantly negative and several of the $\theta_{1 k}$ coefficients also remain negative. Calculating the indirect long-run effects (Table 3) shows that the majority of them are likewise significantly negative, in line with the rather negative than positive spillover effects, as suggested by the results of the SLX model. Exploring the various test statistics reveals that the log-likelihood ratio clearly favors Model (3) over Model (2), yet, the R-squared value is not significantly larger. Moreover, the residual CD statistic is still significant, and $\alpha$ is still not significantly different from 1 , which jointly lead to a rejection of the model in terms of fully capturing the spatial dependence.

Introducing the dynamic model in Column (4) shows a somewhat different picture for the $\rho$ coefficient, which now turns significantly positive. The likewise positive significant value of $\tau$ suggests serial correlation in the number of deaths. The direct effects are again consistently positive and statistically significant after eleven days, while the indirect effects are again first primarily negative, both in the short- and in the long-run and only turn positive after a lag of eleven days. R-squared becomes somewhat larger in comparison to the static model and also the log-likelihood ratio test rejects the static model in favor of the dynamic model. ${ }^{7}$ Nevertheless, the CD-test statistic still lies outside of the $[-1.96 ; 1.96]$ interval and the confidence intervals of the cross-sectional exponent $\alpha$ still include the value 1, making the dynamic SDM with fixed effects also unsuitable to fully capture the strong cross-sectional dependence. Another aspect leading to a rejection of the model is the increasing size (in absolute terms) of both the direct and indirect effect. Given that several federal states implemented cautionary measures to de-link the number of infections and death cases, one would plausibly expect a decrease in the effect sizes over time.

\footnotetext{
${ }^{7}$ The likelihood ratio test is based on comparing the Log Likelihood between Model (3) and (4) with 2 degrees of freedom. Since this could be considered not fully adequate since the two models are estimated with a different number of observations, I redo the LR test by (i) dropping the (timewise) first observation of Model (3) such that it is also estimated with only 3904 observations and (ii) by including the observation of the last day in April, such that model (4) is estimated with 3920 observations. In both cases, Model (4) is the preferred specification.
} 
Table 2: Estimation results of the lag between Covid-19 infections and deaths using different model specifications

\begin{tabular}{|c|c|c|c|c|c|}
\hline & $\begin{array}{c}(1) \\
\text { Fixed } \\
\text { Effects }\end{array}$ & $\begin{array}{l}\text { (2) } \\
\text { SLX }\end{array}$ & $\begin{array}{c}\text { (3) } \\
\text { Static SDM } \\
\text { with fixed } \\
\text { effects } \\
\end{array}$ & $\begin{array}{c}(4) \\
\text { Dynamic SDM } \\
\text { with fixed } \\
\text { effects } \\
\end{array}$ & $\begin{array}{c}(5) \\
\text { Dynamic SDM } \\
\text { with CSA }\end{array}$ \\
\hline Deaths t-1 $(\tau)$ & & & & $\begin{array}{c}0.178 * * * \\
(0.044)\end{array}$ & $\begin{array}{l}-0.069 * \\
(0.041)\end{array}$ \\
\hline WDeaths t $(\rho)$ & & & $\begin{array}{c}-0.179 * * * \\
(0.023)\end{array}$ & $\begin{array}{c}0.173 * * * \\
(0.021)\end{array}$ & $\begin{array}{c}0.076^{* * * *} \\
(0.024)\end{array}$ \\
\hline WDeaths t-1 $(\eta)$ & & & & $\begin{array}{c}0.010 \\
(0.026)\end{array}$ & $\begin{array}{c}0.047 \\
(0.034)\end{array}$ \\
\hline Infections t & $\begin{array}{c}0.017 * * * \\
(0.003)\end{array}$ & $\begin{array}{c}0.016 * * * \\
(0.002)\end{array}$ & $\begin{array}{c}0.016 * * * \\
(0.002)\end{array}$ & $\begin{array}{c}0.016 * * * \\
(0.002)\end{array}$ & $\begin{array}{c}0.013 * * * \\
(0.002)\end{array}$ \\
\hline Infections t-1 & $\begin{array}{c}-0.002 * * \\
(0.001)\end{array}$ & $\begin{array}{c}-0.002^{* *} \\
(0.001)\end{array}$ & $\begin{array}{c}-0.002 * * \\
(0.001)\end{array}$ & $\begin{array}{c}-0.005 * * * \\
(0.001)\end{array}$ & $\begin{array}{c}-0.003 * * * \\
(0.001)\end{array}$ \\
\hline Infections t-2 & $\begin{array}{c}0.000 \\
(0.001)\end{array}$ & $\begin{array}{c}0.001 \\
(0.000)\end{array}$ & $\begin{array}{l}0.001^{*} \\
(0.000)\end{array}$ & $\begin{array}{c}0.001 * * * \\
(0.000)\end{array}$ & $\begin{array}{l}-0.000 \\
(0.000)\end{array}$ \\
\hline Infections $\mathrm{t}-3$ & $\begin{array}{c}0.000 \\
(0.001)\end{array}$ & $\begin{array}{c}0.000 \\
(0.001)\end{array}$ & $\begin{array}{c}0.000 \\
(0.001)\end{array}$ & $\begin{array}{c}0.000 \\
(0.001)\end{array}$ & $\begin{array}{c}0.000 \\
(0.000)\end{array}$ \\
\hline Infections t-4 & $\begin{array}{c}0.001 \\
(0.001)\end{array}$ & $\begin{array}{c}0.000 \\
(0.001)\end{array}$ & $\begin{array}{c}0.000 \\
(0.001)\end{array}$ & $\begin{array}{c}0.000 \\
(0.000)\end{array}$ & $\begin{array}{l}-0.000 \\
(0.000)\end{array}$ \\
\hline Infections t-5 & $\begin{array}{c}0.001 \\
(0.001)\end{array}$ & $\begin{array}{c}0.001 \\
(0.001)\end{array}$ & $\begin{array}{c}0.001 \\
(0.001)\end{array}$ & $\begin{array}{c}0.001 \\
(0.001)\end{array}$ & $\begin{array}{c}-0.001 * \\
(0.001)\end{array}$ \\
\hline Infections t-6 & $\begin{array}{c}-0.000 \\
(0.001)\end{array}$ & $\begin{array}{c}0.000 \\
(0.001)\end{array}$ & $\begin{array}{c}0.000 \\
(0.001)\end{array}$ & $\begin{array}{c}0.000 \\
(0.001)\end{array}$ & $\begin{array}{c}-0.003 * * * \\
(0.001)\end{array}$ \\
\hline Infections t-7 & $\begin{array}{c}0.000 \\
(0.000)\end{array}$ & $\begin{array}{c}0.000 \\
(0.000)\end{array}$ & $\begin{array}{c}0.000 \\
(0.000)\end{array}$ & $\begin{array}{c}0.000 \\
(0.000)\end{array}$ & $\begin{array}{c}-0.001 * * \\
(0.001)\end{array}$ \\
\hline Infections t- 8 & $\begin{array}{c}0.002 * * * \\
(0.000)\end{array}$ & $\begin{array}{c}0.001 * * * \\
(0.000)\end{array}$ & $\begin{array}{c}0.001 * * * \\
(0.000)\end{array}$ & $\begin{array}{c}0.001 * * \\
(0.000)\end{array}$ & $\begin{array}{c}0.002 * * * \\
(0.000)\end{array}$ \\
\hline Infections t-9 & $\begin{array}{c}-0.005 * * * \\
(0.002)\end{array}$ & $\begin{array}{c}-0.005^{* * *} \\
(0.002)\end{array}$ & $\begin{array}{c}-0.005^{* * *} \\
(0.001)\end{array}$ & $\begin{array}{c}-0.005^{* * *} \\
(0.002)\end{array}$ & $\begin{array}{c}-0.002 * * * \\
(0.000)\end{array}$ \\
\hline Infections t-10 & $\begin{array}{c}-0.003 * * * \\
(0.001)\end{array}$ & $\begin{array}{c}-0.002 * * * \\
(0.001)\end{array}$ & $\begin{array}{c}-0.002 * * * \\
(0.001)\end{array}$ & $\begin{array}{c}-0.002 * * \\
(0.001)\end{array}$ & $\begin{array}{l}-0.001 * \\
(0.000)\end{array}$ \\
\hline Infections t-11 & $\begin{array}{c}0.001 * * \\
(0.001)\end{array}$ & $\begin{array}{c}0.002 * * \\
(0.001)\end{array}$ & $\begin{array}{c}0.002 * * * \\
(0.001)\end{array}$ & $\begin{array}{c}0.002 * * * \\
(0.001)\end{array}$ & $\begin{array}{l}-0.000 \\
(0.000)\end{array}$ \\
\hline Infections t-12 & $\begin{array}{c}0.006^{* * *} \\
(0.001)\end{array}$ & $\begin{array}{c}0.006 * * * \\
(0.001)\end{array}$ & $\begin{array}{c}0.006 * * * \\
(0.001)\end{array}$ & $\begin{array}{c}0.006 * * * \\
(0.001)\end{array}$ & $\begin{array}{c}0.002 * * * \\
(0.000)\end{array}$ \\
\hline Infections t-13 & $\begin{array}{c}0.005^{* *} \\
(0.002)\end{array}$ & $\begin{array}{c}0.005 * * * \\
(0.002)\end{array}$ & $\begin{array}{c}0.005 * * * \\
(0.002)\end{array}$ & $\begin{array}{c}0.004 * * \\
(0.002)\end{array}$ & $\begin{array}{c}0.003 * * * \\
(0.001)\end{array}$ \\
\hline Infections t-14 & $\begin{array}{c}0.005 * * * \\
(0.002)\end{array}$ & $\begin{array}{c}0.005 * * * \\
(0.002)\end{array}$ & $\begin{array}{c}0.005 * * * \\
(0.002)\end{array}$ & $\begin{array}{c}0.004 * * * \\
(0.001)\end{array}$ & $\begin{array}{c}0.004 * * * \\
(0.001)\end{array}$ \\
\hline WInfections t & & $\begin{array}{c}-0.002 * * * \\
(0.001)\end{array}$ & $\begin{array}{c}0.000 \\
(0.000)\end{array}$ & $\begin{array}{c}0.001 * * \\
(0.000)\end{array}$ & $\begin{array}{c}0.000 \\
(0.001)\end{array}$ \\
\hline WInfections t-1 & & $\begin{array}{c}0.000 \\
(0.000)\end{array}$ & $\begin{array}{l}-0.000 \\
(0.000)\end{array}$ & $\begin{array}{l}-0.000 \\
(0.001)\end{array}$ & $\begin{array}{c}0.000 \\
(0.000)\end{array}$ \\
\hline WInfections t-2 & & $\begin{array}{c}0.002 * * \\
(0.001)\end{array}$ & $\begin{array}{c}0.002 * * * \\
(0.001)\end{array}$ & $\begin{array}{c}0.002 * * * \\
(0.001)\end{array}$ & $\begin{array}{c}0.003 * * * \\
(0.001)\end{array}$ \\
\hline WInfections t-3 & & $\begin{array}{c}-0.002 * * * \\
(0.000)\end{array}$ & $\begin{array}{c}-0.002 * * * \\
(0.000)\end{array}$ & $\begin{array}{c}-0.002 * * * \\
(0.000)\end{array}$ & $\begin{array}{c}0.001 * * \\
(0.000)\end{array}$ \\
\hline WInfections t-4 & & $\begin{array}{c}-0.005^{* * *} \\
(0.001)\end{array}$ & $\begin{array}{c}-0.004 * * * \\
(0.001)\end{array}$ & $\begin{array}{c}-0.004 * * * \\
(0.001)\end{array}$ & $\begin{array}{l}-0.000 \\
(0.000)\end{array}$ \\
\hline WInfections t-5 & & $\begin{array}{c}-0.001 * * * \\
(0.000)\end{array}$ & $\begin{array}{c}-0.002 * * * \\
(0.000)\end{array}$ & $\begin{array}{c}-0.001 * \\
(0.000)\end{array}$ & $\begin{array}{c}0.001 \\
(0.001)\end{array}$ \\
\hline WInfections t-6 & & $\begin{array}{c}0.000 \\
(0.000)\end{array}$ & $\begin{array}{l}-0.000 \\
(0.001)\end{array}$ & $\begin{array}{c}0.000 \\
(0.000)\end{array}$ & $\begin{array}{c}0.002 * * * \\
(0.001)\end{array}$ \\
\hline WInfections t-7 & & $\begin{array}{l}-0.000 \\
(0.001)\end{array}$ & $\begin{array}{c}0.000 \\
(0.001)\end{array}$ & $\begin{array}{l}-0.000 \\
(0.001)\end{array}$ & $\begin{array}{c}0.001 \\
(0.001)\end{array}$ \\
\hline WInfections t-8 & & $\begin{array}{c}-0.003 * * * \\
(0.001)\end{array}$ & $\begin{array}{c}-0.002 * * * \\
(0.001)\end{array}$ & $\begin{array}{c}-0.002 * * * \\
(0.001)\end{array}$ & $\begin{array}{c}-0.002 * * * \\
(0.000)\end{array}$ \\
\hline WInfections t-9 & & $\begin{array}{l}-0.001 \\
(0.001)\end{array}$ & $\begin{array}{l}-0.001 \\
(0.001)\end{array}$ & $\begin{array}{l}-0.001 \\
(0.001)\end{array}$ & $\begin{array}{l}-0.000 \\
(0.000)\end{array}$ \\
\hline WInfections t-10 & & -0.001 & -0.000 & -0.000 & -0.000 \\
\hline
\end{tabular}




\begin{tabular}{|c|c|c|c|c|c|}
\hline \multirow{2}{*}{ WInfections t-11 } & & $(0.001)$ & $(0.001)$ & $(0.001)$ & $(0.000)$ \\
\hline & & $0.002 * * *$ & $0.003 * * *$ & $0.003 * * *$ & $0.001 * * *$ \\
\hline \multirow{3}{*}{ WInfections t-12 } & & $(0.000)$ & $(0.000)$ & $(0.000)$ & $(0.000)$ \\
\hline & & $0.001 * * *$ & $0.002 * * *$ & $0.001 * * *$ & $-0.001 * *$ \\
\hline & & $(0.000)$ & $(0.000)$ & $(0.000)$ & $(0.000)$ \\
\hline \multirow[t]{2}{*}{ WInfections t-13 } & & 0.001 & $0.001 * *$ & 0.001 & $-0.002 * *$ \\
\hline & & $(0.001)$ & $(0.001)$ & $(0.001)$ & $(0.001)$ \\
\hline \multirow[t]{2}{*}{ WInfections t-14 } & & $-0.001 * *$ & -0.000 & -0.000 & $-0.002 * * *$ \\
\hline & & $(0.000)$ & $(0.000)$ & $(0.000)$ & $(0.000)$ \\
\hline $\mathrm{R}^{2}$ (overall, incl. FE) & 0.807 & 0.814 & 0.814 & 0.824 & 0.849 \\
\hline Log Likelihood & 2409.24 & 2489.42 & 2522.59 & 2567.47 & 3285.29 \\
\hline Residual CD-Test & -9.858 & -9.86 & 10.71 & 11.06 & -0.94 \\
\hline Avg. Corr. Coef. & -0.057 & -0.058 & 0.062 & 0.065 & -0.005 \\
\hline CS-exponent $\alpha$ of & 0.50 & 0.34 & 0.76 & 0.77 & 0.73 \\
\hline residuals [Conf. Inter] & {$[-0.07 ; 1.07]$} & {$[-1.48 ; 2.16]$} & {$[0.15 ; 1.07]$} & {$[0.44 ; 1.11]$} & {$[0.57 ; 0.90]$} \\
\hline & & (1) vs. (2) & (2) vs. (3) & (3) vs. (4) ${ }^{1}$ & (4) vs. (5) \\
\hline LR-test (p-value) & & $<0.001$ & $<0.001$ & $<0.001$ & $<0.001$ \\
\hline Number of Obs. & 3920 & 3920 & 3920 & 3904 & 3904 \\
\hline Number of Fed. States & 16 & 16 & 16 & 16 & 16 \\
\hline
\end{tabular}

Notes: Robust Driscoll and Kraay standard errors in parenthesis. ***p<0.01, **p<0.05, *p<0.1. Models (1) and (2) are estimated via OLS. All other models are estimated via Quasi-Maximum Likelihood. The Yu et al. (2008) bias-correction is applied in Model (4) and (5). The Stata command xsmle (Belotti et al., 2014) is used to estimate the spatial models. $\mathrm{R}^{2}$ statistics show the corrected overall $\mathrm{R}^{2}$ including the variation explained by the fixed-effects to be comparable across all five models. ${ }^{1}$ The likelihood ratio test is based on comparing the Log Likelihood between Model (3) and (4) with 2 degrees of freedom. Since this could be considered not fully adequate since the two models are estimated with a different number of observations, I redo the LR test by (i) dropping the (timewise) first observation of Model (3) such that it is also estimated with only 3904 observations and (ii) by including the observation of the last day in April, such that model (4) is estimated with 3920 observations. In both cases, Model (4) is the preferred specification.

The only model that is well suited to fully capture the cross-sectional dependence in the data is the dynamic SDM with cross-sectional averages presented in Column (5), which aligns with the crosssectional exponent $\alpha$ of nearly one that was estimated for the raw data. R-squared and the log-likelihood value both take on the largest value in this model and the residual CD-test statistic lies within the [-1.96; 1.96] interval and is, hence, no longer significant. The average correlation coefficient of the residuals is now close to zero (-0.005) and the cross-sectional exponent alpha is now significantly different from 1 , with the point estimate below the threshold of $3 / 4$, which indicates that common factors have adequately been addressed (Ciccarelli and Elhorst, 2018). Moreover, the sum of $\tau, \eta$ and $\rho$ is smaller than 1, which is essential for the model to be stationary. $\tau$ is statistically significant and negative, supporting again the hypothesis of mortality displacement, i.e., days with high numbers of death cases are followed by days with on average lower numbers of death cases.

Several of the $\theta_{1 k}$ coefficients as well as the coefficient $\rho$ and are statistically significant, $\eta$ remains insignificant, yet, a LR-test rejects that this variable can be dropped from the model. The significant 
coefficients jointly indicate that global short-run and long-run spillover effects are present. Interestingly,

and in contrast to the model in Ciccarelli and Elhorst (2018), the model does only account for the full cross-sectional dependence when cross-sectional averages of both the dependent and the independent variables are included. Including only the cross-sectional averages of the current and lagged independent variable results in a residual CD-test statistic that is still outside the required interval.

Table 3 shows that the direct effects of increases in the own-state infections are, as expected, positive and significant, which is in line with the hypothesis that increases in infections are followed by increases in deaths. Regarding the size, an increase in the number of infections by 1,000 per 100,000 leads to an additional one to three deaths cases in the same state. The time lag between an increase in infections and a subsequent increase in death cases can now be determined at approximately 12 days. Before the $12^{\text {th }}$ lag, the coefficients for both, the direct and the total effect switch between a negative and positive sign, but become consistently positive afterwards in each of the five models.

The estimated indirect effects also remain significantly negative (now even for the longer lags after eleven days) in Model (5), supporting the previous two models in the hypothesis that increases in infection rates in other states decrease own-state death cases. These negative spillover effects might seem counterintuitive at first, but could be an indicator that states choose to implement stricter preventive policy measures in their own state when the infections in other states rise (assuming that own infection rates would remain constant). This finding is also well in line with previous studies. Ehlert (2021), for example, finds that in a given German district the number of deaths and infections shrink with higher numbers in early Covid-19 infections in neighboring districts. Krisztin et al. (2020) also find a temporarily negative degree of global spatial autocorrelation and explain their finding with temporary travel bans to regions with excessive infection rates to prevent transmission to the own country. Nevertheless, these negative spillovers seem to contradict the infectious nature of the virus and should be investigated in further detail in future studies to assess whether the hypothesis of negative spillovers caused by stricter policy measures can be confirmed. 
Table 3: Direct effects and spillover effects for infections in the short-run (SR) and long-run (LR)

\begin{tabular}{|c|c|c|c|c|c|c|c|}
\hline & & SR Direct & SR Indirect & SR Total & LR Direct & LR Indirect & LR Total \\
\hline \multirow{15}{*}{ SLX } & Infections t & & & & $0.016^{* * *}$ & $-0.002 * * *$ & \\
\hline & Infections t-1 & & & & $-0.002 * *$ & 0.000 & \\
\hline & Infections t-2 & & & & 0.001 & $0.002 * *$ & \\
\hline & Infections t-3 & & & & 0.000 & $-0.002 * * *$ & \\
\hline & Infections t-4 & & & & 0.000 & $-0.005 * * *$ & \\
\hline & Infections t-5 & & & & 0.001 & $-0.001 * * *$ & \\
\hline & Infections t-6 & & & & 0.000 & 0.000 & \\
\hline & Infections t-7 & & & & 0.000 & -0.000 & \\
\hline & Infections t- 8 & & & & $0.001 * * *$ & $-0.003 * * *$ & \\
\hline & Infections t-9 & & & & $-0.005^{* * *}$ & -0.001 & \\
\hline & Infections t-10 & & & & $-0.002 * * *$ & -0.001 & \\
\hline & Infections t-11 & & & & $0.002 * *$ & $0.002 * * *$ & \\
\hline & Infections t-12 & & & & $0.006 * * *$ & $0.001 * * *$ & \\
\hline & Infections t-13 & & & & $0.005 * * *$ & 0.001 & \\
\hline & Infections t-14 & & & & $0.005^{* * *}$ & $-0.001 * *$ & \\
\hline \multirow{15}{*}{$\begin{array}{c}\text { S-SDM- } \\
\text { FE }\end{array}$} & Infections t & & & & $0.017 * * *$ & $-0.002 * * *$ & $0.014 * * *$ \\
\hline & Infections t-1 & & & & $-0.002 * *$ & 0.000 & $-0.002 * *$ \\
\hline & Infections t-2 & & & & 0.001 & $0.002 * *$ & $0.002 * * *$ \\
\hline & Infections t-3 & & & & 0.000 & $-0.002 * * *$ & $-0.002 * * *$ \\
\hline & Infections t- 4 & & & & 0.000 & $-0.004 * * *$ & $-0.004 * * *$ \\
\hline & Infections t-5 & & & & 0.001 & $-0.002 * * *$ & -0.001 \\
\hline & Infections t- 6 & & & & 0.000 & -0.000 & 0.000 \\
\hline & Infections t-7 & & & & 0.000 & 0.000 & 0.000 \\
\hline & Infections t- 8 & & & & $0.001 * * *$ & $-0.002 * * *$ & $-0.001 * *$ \\
\hline & Infections t-9 & & & & $-0.005 * * *$ & -0.000 & $-0.005 * * *$ \\
\hline & Infections t-10 & & & & $-0.003 * * *$ & 0.000 & $-0.002 * *$ \\
\hline & Infections t-11 & & & & $0.002 * * *$ & $0.002 * * *$ & $0.004 * * *$ \\
\hline & Infections t-12 & & & & $0.006 * * *$ & $0.001 * *$ & $0.007 * * *$ \\
\hline & Infections t-13 & & & & $0.005 * * *$ & 0.000 & $0.005 * * *$ \\
\hline & Infections $\mathrm{t}-14$ & & & & $0.005^{* * *}$ & $-0.001 * *$ & $0.004 * * *$ \\
\hline \multirow{15}{*}{$\begin{array}{c}\text { D-SDM- } \\
\text { FE }\end{array}$} & Infections t & $0.016 * * *$ & $-0.002 * * *$ & $0.015^{* * *}$ & $0.020 * * *$ & $-0.003 * * *$ & $0.017 * * *$ \\
\hline & Infections t-1 & $-0.005 * * *$ & 0.001 & $-0.004 * * *$ & $-0.006 * * *$ & 0.001 & $-0.005 * * *$ \\
\hline & Infections t-2 & $0.001 * *$ & $0.002 * * *$ & $0.003 * * *$ & $0.001 * *$ & $0.002 * * *$ & $0.003 * * *$ \\
\hline & Infections t-3 & 0.000 & $-0.002 * * *$ & $-0.002 * * *$ & 0.000 & $-0.003 * * *$ & $-0.002 * * *$ \\
\hline & Infections t-4 & 0.000 & $-0.004 * * *$ & $-0.003 * * *$ & 0.000 & $-0.004 * * *$ & $-0.004 * * *$ \\
\hline & Infections t-5 & 0.001 & $-0.001 * *$ & 0.000 & 0.001 & $-0.001 * *$ & 0.000 \\
\hline & Infections t-6 & 0.000 & 0.000 & 0.000 & 0.000 & 0.000 & 0.000 \\
\hline & Infections t-7 & 0.000 & -0.000 & 0.000 & 0.000 & -0.000 & 0.000 \\
\hline & Infections t- 8 & $0.001 * * *$ & $-0.002 * * *$ & $-0.001 * *$ & $0.001 * * *$ & $-0.003 * * *$ & $-0.001 * *$ \\
\hline & Infections t-9 & $-0.005 * * *$ & 0.000 & $-0.005^{* * *}$ & $-0.006 * * *$ & 0.000 & $-0.006 * * *$ \\
\hline & Infections $\mathrm{t}-10$ & $-0.002 * *$ & 0.000 & -0.002 & $-0.002 * *$ & 0.000 & -0.002 \\
\hline & Infections t-11 & $0.002 * * *$ & $0.002 * * *$ & $0.004 * * *$ & $0.002 * * *$ & $0.003 * * *$ & $0.005 * * *$ \\
\hline & Infections t-12 & $0.006 * * *$ & 0.000 & $0.006 * * *$ & $0.007 * * *$ & 0.000 & $0.007 * * *$ \\
\hline & Infections t-13 & $0.004 * *$ & 0.000 & $0.004 * * *$ & $0.005 * *$ & 0.000 & $0.005 * * *$ \\
\hline & Infections t-14 & $0.004 * * *$ & $-0.001 * * *$ & $0.003 * *$ & $0.005 * * *$ & $-0.001 * * *$ & $0.004 * *$ \\
\hline \multirow{15}{*}{$\begin{array}{l}\text { D-SDM- } \\
\text { CSA }\end{array}$} & Infections t & $0.013 * * *$ & $-0.001 * *$ & $0.012 * * *$ & $0.012 * * *$ & -0.000 & $0.012 * * *$ \\
\hline & Infections t-1 & $-0.003 * * *$ & 0.001 & $-0.002 * * *$ & $-0.003 * * *$ & 0.001 & $-0.002 * * *$ \\
\hline & Infections t-2 & -0.000 & $0.003 * * *$ & $0.003 * * *$ & -0.000 & $0.003 * * *$ & $0.003 * * *$ \\
\hline & Infections t-3 & 0.000 & $0.001 *$ & $0.001 * *$ & 0.000 & $0.001 * *$ & $0.001 * *$ \\
\hline & Infections t-4 & -0.000 & -0.000 & $-0.001 * *$ & -0.000 & -0.000 & $-0.001 * *$ \\
\hline & Infections t-5 & $-0.001 *$ & 0.001 & -0.000 & $-0.001 *$ & 0.001 & -0.000 \\
\hline & Infections t-6 & $-0.003 * * *$ & $0.002 * * *$ & $-0.001 * * *$ & $-0.003 * * *$ & $0.002 * * *$ & $-0.001 * * *$ \\
\hline & Infections t-7 & $-0.001 * *$ & 0.001 & -0.000 & $-0.001 * *$ & 0.001 & -0.000 \\
\hline & Infections t- 8 & $0.002 * * *$ & $-0.002 * * *$ & 0.000 & $0.002 * * *$ & $-0.002 * * *$ & 0.000 \\
\hline & Infections t-9 & $-0.002 * * *$ & -0.000 & $-0.002 * * *$ & $-0.002 * * *$ & -0.000 & $-0.002 * * *$ \\
\hline & Infections t-10 & $-0.001 *$ & -0.000 & $-0.001 *$ & $-0.001 *$ & -0.000 & $-0.001 *$ \\
\hline & Infections t-11 & -0.000 & $0.001 * * *$ & 0.000 & -0.000 & $0.001 * * *$ & 0.000 \\
\hline & Infections t-12 & $0.002 * * *$ & $-0.001 * *$ & $0.001 * * *$ & $0.002 * * *$ & $-0.001 * *$ & $0.001 * * *$ \\
\hline & Infections t-13 & $0.003 * * *$ & $-0.002 * *$ & 0.000 & $0.002 * * *$ & $-0.002 * *$ & 0.000 \\
\hline & Infections t-14 & $0.004 * * *$ & $-0.002 * * *$ & $0.001 * *$ & $0.003 * * *$ & $-0.002 * * *$ & $0.001 * *$ \\
\hline
\end{tabular}

Notes: Table 3 shows the marginal direct and spillover effects for infections, in the short-run and long-run for every spatial model from day $\mathrm{t}$ to day $\mathrm{t}-14$. Marginal direct (indirect) effects are derived from the mean diagonal (off-diagonal) elements of the respective model's matrix of partial derivates (LeSage and Pace, 2009; Debarsy et al., 2012; Elhorst, 2014; Elhorst, 2021). $* * * p<0.01, * * p<0.05, * p<0.1$. Standard errors are obtained via Monte Carlo Simulation as described in LeSage and Pace (2009) (see also Belotti et al., 2017, and Elhorst, 2021). SLX: Spatial lag of X model; S-SDM-FE: Static Spatial Durbin Model with time and spatial fixed effects; D-SDM-FE: Dynamic Spatial Durbin Model with time and spatial fixed effects; D-SDM-CSA: Dynamic Spatial Durbin Model with Cross-Sectional Averages; SR: short-run; LR: long-run. 
The size of the short-run (SR) and long-run (LR) effects for the preferred Model (5) is now also in line

with the theoretical considerations, as they show that the size of all three types of effects becomes smaller in size over time. While this is somewhat blurred in Table 3 given the decimal rounding, taking a closer look reveals that the direct effect after 14 days in the short-run (equal to 0.0036 ) is reduced by $10 \%$ to 0.0033 in the long-run. The same pattern is found for the indirect effect; for example, the indirect short-run effect after 14 days is equal -0.0022 but is reduced in absolute terms to -0.0020 . This reduction in absolute size indicates that policy measures that have been taken in the time horizon considered in this study seem to have been effective in protecting the most vulnerable individuals and thereby have slightly weakened the link between the rising number of infections from the rising number of death cases.

The coefficients for temperature remain insignificant in every model and both, the short-run and longrun direct and indirect effects are essentially zero (shown in Table A2 in the Appendix). Hence, in contrast to studies in different settings (Ma et al., 2020; Wu et al., 2020), temperature seems not to affect the number of daily deaths in Germany. Yet, this can at least to some extent be explained by the inclusion of time fixed-effects or common factors, respectively, as they absorb a substantial part of the within-day variation in temperature across states. The number of patients being treated in intensive care seems to relate to the number of deaths (Table A2 in the Appendix), yet no clear positive or negative pattern emerges.

\section{Conclusion}

The severe restrictions and policies that are implemented to limit the dynamic spread of Covid-19 require a continuous evaluation to assess their effectiveness. In this regard, the case fatality ratio is one of the most important quantitative measures (WHO, 2020; Ioannidis, 2021). Yet, its calculation requires an exact estimate of the time lag between infections and deaths. In this article, I analyze this lag using daily spatial panel data of the 16 German federal states over the period May 2020 to December 2020. My results suggest that the curve of death cases follows the curve of infections with a lag of approximately 12 days. 
Moreover, to account for the spatial spread of the virus, I use spatial econometric models that allow for exogenous and endogenous spillover effects between states. I find that only the dynamic Spatial Durbin Model with state-fixed effects and cross-sectional averages can fully capture the strong cross-sectional dependence found in the data. While the overall effect is largely positive across the different models, the direct and indirect effects differ in sign. The direct effects show that an increase in infections within a given state leads to an increase in the number of reported death cases after about 12 days. Contrarily, the indirect effects (spillovers) are significantly negative, indicating that an increase in infections in neighboring states (and via the global spillovers also in all other states) reduces the number of death cases in that given state. This could be explained by preventive measures taken by the state government as soon as they observe rising infections in other states. While this is well line with the findings of earlier studies (Krisztin et al., 2020; Ehlert, 2021), future studies will be needed to confirm this hypothesis and to investigate the causal underlying reasons in more detail. 


\section{References}

Bai, J. (2009). Panel data models with interactive fixed effects. Econometrica, 77(4), 1229-1279.

Bai, J., Li, K. (2021). Dynamic spatial panel data models with common shocks. Journal of Econometrics, 224(1), 134-160.

Bailey, N., Kapetanios, G., Pesaran, M.H. (2016). Exponent of cross-sectional dependence: estimation and inference. Journal of Applied Econometrics, 31(6), 929-960.

Baud, D., Qi, X., Nielsen-Saines, K., Musso, D., Pomar, L., Favre, G. (2020). Real estimates of mortality following COVID-19 infection. The Lancet Infectious Diseases, 20(7), 773.

Belotti, F., Hughes, G., Mortari, A.P. (2017). Spatial panel-data models using Stata. The Stata Journal, $17(1), 139-180$.

Cerqua, A., Di Stefano, R., Letta, M., Miccoli, S. (2021). Was there a COVID-19 harvesting effect in Northern Italy?.[Preprint] arXiv. https://arxiv.org/abs/2103.01812v3.

Chrusciel, P., Szybka, S. (2021). On the lag between deaths and infections in the first phase of the Covid19 pandemic. [Preprint] medRxiv. https://doi.org/10.1101/2021.01.01.21249115.

Ciccarelli, C., Elhorst, J.P. (2018). A dynamic spatial econometric diffusion model with common factors: The rise and spread of cigarette consumption in Italy. Regional Science and Urban Economics, $72,131-142$

Debarsy, N., Ertur, C., LeSage, J.P. (2012). Interpreting dynamic space-time panel data models. Statistical Methodology, 9(1-2), 158-171. 
Deschênes, O., Moretti, E. (2009). Extreme weather events, mortality, and migration. The Review of Economics and Statistics, 91(4), 659-681.

Driscoll, J.C., Kraay, A.C. (1998). Consistent covariance matrix estimation with spatially dependent panel data. Review of Economics and Statistics, 80(4), 549-560.

Ehlert, A. (2021). The socio-economic determinants of COVID-19: a spatial analysis of German county level data. Socio-Economic Planning Sciences, 101083.

Elhorst, J.P. (2021). Spatial Panel Models and Common Factors. In: Fischer, M., Nijkamp, P. (eds). Handbook of Regional Science. Berlin, Heidelberg: Springer.

Elhorst, J.P. (2014). Spatial econometrics from cross-sectional data to spatial panels. Heidelberg, New York, Dordrecht, London: Springer.

Elhorst, J.P., Gross, M., Tereanu, E. (2021). Cross-sectional dependence and spillovers in space and time: where spatial econometrics and Global VAR models meet. Journal of Economic Surveys, 35(1), 192-226.

Golgher, A.B., Voss, P.R. (2016). How to interpret the coefficients of spatial models: Spillovers, direct and indirect effects. Spatial Demography, 4(3), 175-205.

Guan, W.J., Ni, Z.Y., Hu, Y., Liang, W.H., Ou, C.Q., He, J.X., et al. (2020). Clinical characteristics of coronavirus disease 2019 in China. New England Journal of Medicine, 382(18), 1708-1720.

Guliyev, H. (2020). Determining the spatial effects of COVID-19 using the spatial panel data model. Spatial Statistics, 38, 100443. 
Halleck Vega, S., Elhorst, J.P. (2016). A regional unemployment model simultaneously accounting for serial dynamics, spatial dependence and common factors. Regional Science and Urban Economics, 60(C), 85-95.

Hoechle, D. (2007). Robust standard errors for panel regressions with cross-sectional dependence. The Stata Journal, 7(3), 281-312.

Ioannidis, J.P. (2021). Infection fatality rate of COVID-19 inferred from seroprevalence data. Bulletin of the World Health Organization, 99(1), 19-33.

Karlsson, M., Ziebarth, N.R. (2018). Population health effects and health-related costs of extreme temperatures: Comprehensive evidence from Germany. Journal of Environmental Economics and Management, 91, 93-117.

Kim, D.D., Goel, A. (2020). Estimating case fatality rates of COVID-19. The Lancet Infectious Diseases, 20(7), 773-774.

Krisztin, T., Piribauer, P., Wögerer, M. (2020). The spatial econometrics of the coronavirus pandemic. Letters in Spatial and Resource Sciences, 13(3), 209-218.

Lee, L.F., Yu, J. (2010). A spatial dynamic panel data model with both time and individual fixed effects. Econometric Theory, 26(2), 564-597.

LeSage, J.P., Pace, R.K. (2009). Introduction to Spatial Econometrics. Boca Raton, FL: Taylor and Francis.

Ma, Y., Zhao, Y., Liu, J., He, X., Wang, B., Fu, S., et al. (2020). Effects of temperature variation and humidity on the death of COVID-19 in Wuhan, China. Science of the Total Environment, 724, 138226. 
Martinez, M.E. (2018). The calendar of epidemics: seasonal cycles of infectious diseases. PLoS Pathogene, 14(11), e1007327.

Michelozzi, P., de'Donato, F., Scortichini, M., Pezzotti, P., Stafoggia, M., De Sario, M., et al. (2020). Temporal dynamics in total excess mortality and COVID-19 deaths in Italian cities. BMC Public Health, 20(1), 1-8.

Pesaran, M.H. (2015). Testing weak cross-sectional dependence in large panels. Econometric Reviews, 34(6-10), 1088-1116.

Pesaran, M.H. (2006). Estimation and inference in large heterogeneous panels with a multifactor error structure. Econometrica, 74(4), 967-1012.

Pesaran, M.H. (2004). General diagnostic tests for cross-sectional dependence in panels. IZA Discussion Paper No. 1240. IZA Bonn.

Shaman, J., Pitzer, V.E., Viboud, C., Grenfell, B.T., Lipsitch, M. (2010). Absolute humidity and the seasonal onset of influenza in the continental United States. PLoS Biology, 8(2), e1000316.

Shi, W., Lee, L.F. (2017) Spatial dynamic panel data model with interactive fixed effects. Journal of Econometrics, 197, 323-347.

Testa, C., Krieger, N., Chen, J., Hanage, W. (2020). Visualizing the lagged connection between COVID19 cases and deaths in the United States: An animation using per capita state-level data (January 22, 2020-July 8, 2020). The Harvard Center for Population and Development Studies (HCPDS) Working Paper 19, no. 4. Cambridge, Massachusetts. 
Vanella, P., Wiessner, C., Holz, A., Krause, G., Möhl, A., Wiegel, S., et al. (2020). The role of age distribution, time lag between reporting and death and healthcare system capacity on case fatality estimates of COVID-19. [Preprint] medRxiv. https://doi.org/10.1101/2020.05.16.20104117.

WHO - World Health Organization (2020). Estimating mortality from COVID-19. Scientific Brief. https://apps.who.int/iris/bitstream/handle/10665/333642/WHO-2019-nCoV-Sci_Brief-Mortality2020.1-eng.pdf?sequence=1\&isAllowed=y [Last accessed 07 April 2021].

Wilson, N., Kvalsvig, A., Barnard, L.T., Baker, M.G. (2020). Case-fatality risk estimates for COVID19 calculated by using a lag time for fatality. Emerging Infectious Diseases, 26(6), 1339-1341.

Wu, Y., Jing, W., Liu, J., Ma, Q., Yuan, J., Wang, Y., et al. (2020). Effects of temperature and humidity on the daily new cases and new deaths of COVID-19 in 166 countries. Science of the Total Environment, 729, 139051.

Yu, J., De Jong, R., Lee, L.F. (2008). Quasi-maximum likelihood estimators for spatial dynamic panel data with fixed effects when both $\mathrm{n}$ and $\mathrm{T}$ are large. Journal of Econometrics, 146(1), 118-134.

Zhang, Y., Xu, J., Li, H., Cao, B. (2020). A novel coronavirus (COVID-19) outbreak: a call for action. Chest, 157(4), e99-e101. 


\section{Appendix}

Table A1: Estimation results for intensive care patients and temperature using different model specifications

\begin{tabular}{|c|c|c|c|c|c|}
\hline & $\begin{array}{c}\text { (1) } \\
\text { Fixed } \\
\text { Effects }\end{array}$ & $\begin{array}{l}\text { (2) } \\
\text { SLX }\end{array}$ & $\begin{array}{c}\text { (3) } \\
\text { Static SDM } \\
\text { with fixed } \\
\text { effects } \\
\end{array}$ & $\begin{array}{c}\text { (4) } \\
\text { Dynamic SDM } \\
\text { with fixed } \\
\text { effects } \\
\end{array}$ & $\begin{array}{c}\text { (5) } \\
\text { Dynamic } \\
\text { SDM with } \\
\text { CSA }\end{array}$ \\
\hline Intensive $\mathrm{t}$ & $\begin{array}{c}0.005 \\
(0.015)\end{array}$ & $\begin{array}{l}-0.003 \\
(0.012)\end{array}$ & $\begin{array}{l}-0.003 \\
(0.012)\end{array}$ & $\begin{array}{c}0.009 \\
(0.013)\end{array}$ & $\begin{array}{l}-0.014 \\
(0.017)\end{array}$ \\
\hline Intensive t-1 & $\begin{array}{c}-0.089 * * * * \\
(0.021)\end{array}$ & $\begin{array}{c}-0.094 * * * \\
(0.025)\end{array}$ & $\begin{array}{c}-0.096 * * * \\
(0.023)\end{array}$ & $\begin{array}{c}-0.092 * * * \\
(0.025)\end{array}$ & $\begin{array}{c}-0.067 * * * \\
(0.022)\end{array}$ \\
\hline Intensive $\mathrm{t}-2$ & $\begin{array}{c}-0.092 * * * \\
(0.034)\end{array}$ & $\begin{array}{c}-0.092 * * * \\
(0.031)\end{array}$ & $\begin{array}{c}-0.093 * * * \\
(0.029)\end{array}$ & $\begin{array}{c}-0.076 * * * \\
(0.028)\end{array}$ & $\begin{array}{c}-0.048 * * * \\
(0.016)\end{array}$ \\
\hline Intensive $\mathrm{t}-3$ & $\begin{array}{c}-0.041 \\
(0.042)\end{array}$ & $\begin{array}{l}-0.027 \\
(0.042)\end{array}$ & $\begin{array}{l}-0.029 \\
(0.040)\end{array}$ & $\begin{array}{l}-0.012 \\
(0.040)\end{array}$ & $\begin{array}{c}-0.003 \\
(0.031)\end{array}$ \\
\hline Intensive $\mathrm{t}-4$ & $\begin{array}{c}-0.028 * * \\
(0.014)\end{array}$ & $\begin{array}{c}-0.028 * * \\
(0.014)\end{array}$ & $\begin{array}{c}-0.030 * * \\
(0.014)\end{array}$ & $\begin{array}{l}-0.027 * \\
(0.016)\end{array}$ & $\begin{array}{c}0.002 \\
(0.009)\end{array}$ \\
\hline Intensive t-5 & $\begin{array}{c}0.002 \\
(0.030)\end{array}$ & $\begin{array}{l}-0.015 \\
(0.025)\end{array}$ & $\begin{array}{l}-0.016 \\
(0.024)\end{array}$ & $\begin{array}{l}-0.014 \\
(0.022)\end{array}$ & $\begin{array}{l}0.021^{*} \\
(0.012)\end{array}$ \\
\hline Intensive $\mathrm{t}-6$ & $\begin{array}{c}0.076 \\
(0.047)\end{array}$ & $\begin{array}{l}0.072^{*} \\
(0.038)\end{array}$ & $\begin{array}{c}0.071 * * \\
(0.034)\end{array}$ & $\begin{array}{c}0.071 * * \\
(0.030)\end{array}$ & $\begin{array}{c}0.039 * * * \\
(0.014)\end{array}$ \\
\hline Intensive t-7 & $\begin{array}{c}0.099 * * \\
(0.040)\end{array}$ & $\begin{array}{c}0.094 * * * \\
(0.035)\end{array}$ & $\begin{array}{c}0.085 * * * \\
(0.030)\end{array}$ & $\begin{array}{c}0.071 * * \\
(0.031)\end{array}$ & $\begin{array}{c}0.056 * * * \\
(0.020)\end{array}$ \\
\hline Intensive $\mathrm{t}-8$ & $\begin{array}{l}-0.008 \\
(0.021)\end{array}$ & $\begin{array}{l}-0.000 \\
(0.019)\end{array}$ & $\begin{array}{l}-0.000 \\
(0.019)\end{array}$ & $\begin{array}{l}-0.013 \\
(0.022)\end{array}$ & $\begin{array}{l}-0.015 \\
(0.022)\end{array}$ \\
\hline Intensive t-9 & $\begin{array}{c}0.068 * * \\
(0.034)\end{array}$ & $\begin{array}{l}0.073 * \\
(0.038)\end{array}$ & $\begin{array}{l}0.071^{*} \\
(0.037)\end{array}$ & $\begin{array}{c}0.074 * * \\
(0.036)\end{array}$ & $\begin{array}{c}0.047 * * * * \\
(0.010)\end{array}$ \\
\hline Intensive $\mathrm{t}-10$ & $\begin{array}{c}0.052 * * \\
(0.022)\end{array}$ & $\begin{array}{c}0.052 * * \\
(0.022)\end{array}$ & $\begin{array}{c}0.053 * * \\
(0.021)\end{array}$ & $\begin{array}{c}0.042 * * \\
(0.020)\end{array}$ & $\begin{array}{c}0.059 * * * \\
(0.014)\end{array}$ \\
\hline Intensive $\mathrm{t}-11$ & $\begin{array}{c}-0.040 * * \\
(0.015)\end{array}$ & $\begin{array}{c}-0.049 * * * \\
(0.018)\end{array}$ & $\begin{array}{c}-0.056^{* * *} \\
(0.019)\end{array}$ & $\begin{array}{c}-0.065 * * * \\
(0.020)\end{array}$ & $\begin{array}{l}-0.005 \\
(0.016)\end{array}$ \\
\hline Intensive $\mathrm{t}-12$ & $\begin{array}{c}-0.065^{* *} \\
(0.029)\end{array}$ & $\begin{array}{c}-0.061 * * \\
(0.029)\end{array}$ & $\begin{array}{c}-0.059 * * \\
(0.029)\end{array}$ & $\begin{array}{c}-0.051^{*} \\
(0.028)\end{array}$ & $\begin{array}{c}-0.021 \\
(0.013)\end{array}$ \\
\hline Intensive $\mathrm{t}-13$ & $\begin{array}{l}-0.017 \\
(0.033)\end{array}$ & $\begin{array}{l}-0.005 \\
(0.035)\end{array}$ & $\begin{array}{c}0.001 \\
(0.032)\end{array}$ & $\begin{array}{c}0.016 \\
(0.032)\end{array}$ & $\begin{array}{l}-0.012 \\
(0.032)\end{array}$ \\
\hline Intensive t-14 & $\begin{array}{c}0.014 \\
(0.033)\end{array}$ & $\begin{array}{c}0.015 \\
(0.035)\end{array}$ & $\begin{array}{c}0.015 \\
(0.034)\end{array}$ & $\begin{array}{c}0.016 \\
(0.035)\end{array}$ & $\begin{array}{l}-0.000 \\
(0.030)\end{array}$ \\
\hline WIntensive $\mathrm{t}$ & & $\begin{array}{c}-0.002 * * * \\
(0.001)\end{array}$ & $\begin{array}{l}-0.013 \\
(0.025)\end{array}$ & $\begin{array}{l}-0.015 \\
(0.022)\end{array}$ & $\begin{array}{c}0.057 \\
(0.035)\end{array}$ \\
\hline WIntensive t-1 & & $\begin{array}{c}0.000 \\
(0.000)\end{array}$ & $\begin{array}{l}-0.005 \\
(0.021)\end{array}$ & $\begin{array}{l}-0.005 \\
(0.022)\end{array}$ & $\begin{array}{l}0.027 * \\
(0.015)\end{array}$ \\
\hline WIntensive $\mathrm{t}-2$ & & $\begin{array}{c}0.002 * * \\
(0.001)\end{array}$ & $\begin{array}{l}-0.012 \\
(0.015)\end{array}$ & $\begin{array}{l}-0.012 \\
(0.013)\end{array}$ & $\begin{array}{l}-0.016 \\
(0.011)\end{array}$ \\
\hline WIntensive t-3 & & $\begin{array}{c}-0.002 * * * \\
(0.000)\end{array}$ & $\begin{array}{c}0.107 * * * \\
(0.022)\end{array}$ & $\begin{array}{c}0.107 * * * \\
(0.022)\end{array}$ & $\begin{array}{c}0.072 * * * \\
(0.017)\end{array}$ \\
\hline WIntensive t-4 & & $\begin{array}{c}-0.005^{* * *} * \\
(0.001)\end{array}$ & $\begin{array}{l}-0.005 \\
(0.015)\end{array}$ & $\begin{array}{l}-0.022 \\
(0.015)\end{array}$ & $\begin{array}{l}-0.023 \\
(0.018)\end{array}$ \\
\hline WIntensive t-5 & & $\begin{array}{c}-0.001 * * * \\
(0.000)\end{array}$ & $\begin{array}{l}-0.009 \\
(0.024)\end{array}$ & $\begin{array}{l}-0.007 \\
(0.024)\end{array}$ & $\begin{array}{l}-0.008 \\
(0.012)\end{array}$ \\
\hline WIntensive $\mathrm{t}-6$ & & $\begin{array}{c}0.000 \\
(0.000)\end{array}$ & $\begin{array}{l}-0.001 \\
(0.031)\end{array}$ & $\begin{array}{c}0.004 \\
(0.029)\end{array}$ & $\begin{array}{c}0.005 \\
(0.012)\end{array}$ \\
\hline WIntensive t-7 & & $\begin{array}{l}-0.000 \\
(0.001)\end{array}$ & $\begin{array}{c}-0.063 * * \\
(0.029)\end{array}$ & $\begin{array}{c}-0.061 * * \\
(0.027)\end{array}$ & $\begin{array}{c}-0.051 * * \\
(0.026)\end{array}$ \\
\hline WIntensive $\mathrm{t}-8$ & & $\begin{array}{c}-0.003 * * * \\
(0.001)\end{array}$ & $\begin{array}{c}0.052 \\
(0.035)\end{array}$ & $\begin{array}{l}0.063^{*} \\
(0.034)\end{array}$ & $\begin{array}{c}0.019 \\
(0.020)\end{array}$ \\
\hline WIntensive t-9 & & $\begin{array}{l}-0.001 \\
(0.001)\end{array}$ & $\begin{array}{c}0.025 \\
(0.036)\end{array}$ & $\begin{array}{c}0.013 \\
(0.035)\end{array}$ & $\begin{array}{c}-0.038 * * * \\
(0.012)\end{array}$ \\
\hline WIntensive t-10 & & $\begin{array}{l}-0.001 \\
(0.001)\end{array}$ & $\begin{array}{c}0.024 \\
(0.017)\end{array}$ & $\begin{array}{c}0.019 \\
(0.013)\end{array}$ & $\begin{array}{c}-0.057 * \\
(0.035)\end{array}$ \\
\hline WIntensive t-11 & & $\begin{array}{c}0.002 * * * \\
(0.000)\end{array}$ & $\begin{array}{c}-0.041 * * \\
(0.020)\end{array}$ & $\begin{array}{c}-0.046^{* *} * \\
(0.018)\end{array}$ & $\begin{array}{c}-0.048 * * * \\
(0.012)\end{array}$ \\
\hline
\end{tabular}


WIntensive t-12

WIntensive t-13

WIntensive t-14

Temperature

Temperature $\mathrm{t}-1$

Temperature t-2

Temperature $\mathrm{t}-3$

Temperature t-4

Temperature t-5

Temperature $\mathrm{t}-6$

Temperature $\mathrm{t}-7$

Temperature t- 8

Temperature t-9

Temperature t-10

Temperature t-11

Temperature $\mathrm{t}-12$

Temperature t-13

Temperature t-14

WTemperature $\mathrm{t}$

WTemperature t-1

WTemperature t-2

WTemperature t-3

WTemperature t-4

WTemperature t-5

WTemperature t-6

WTemperature t-7

WTemperature t-8

WTemperature t-9

WTemperature t-10

WTemperature t-11

WTemperature t-12

WTemperature t-13

WTemperature t-14

\begin{tabular}{|c|c|c|c|}
\hline $0.001 * * *$ & 0.039 & 0.048 & 0.010 \\
\hline$(0.000)$ & $(0.026)$ & $(0.029)$ & $(0.010)$ \\
\hline 0.001 & $0.149 * *$ & $0.140 * *$ & $0.079 * *$ \\
\hline$(0.001)$ & $(0.066)$ & $(0.065)$ & $(0.033)$ \\
\hline$-0.001 * *$ & 0.047 & 0.022 & 0.025 \\
\hline$(0.000)$ & $(0.043)$ & $(0.040)$ & $(0.029)$ \\
\hline 0.003 & 0.004 & 0.004 & 0.002 \\
\hline$(0.005)$ & $(0.004)$ & $(0.004)$ & $(0.002)$ \\
\hline 0.000 & -0.000 & -0.001 & -0.000 \\
\hline$(0.002)$ & $(0.002)$ & $(0.002)$ & $(0.001)$ \\
\hline-0.002 & -0.001 & -0.002 & 0.001 \\
\hline$(0.002)$ & $(0.002)$ & $(0.002)$ & $(0.001)$ \\
\hline-0.001 & -0.001 & -0.000 & 0.003 \\
\hline$(0.001)$ & $(0.001)$ & $(0.001)$ & $(0.002)$ \\
\hline-0.002 & -0.002 & -0.002 & $-0.003 * *$ \\
\hline$(0.002)$ & $(0.001)$ & $(0.002)$ & $(0.001)$ \\
\hline-0.000 & -0.000 & 0.000 & 0.001 \\
\hline$(0.001)$ & $(0.001)$ & $(0.001)$ & $(0.001)$ \\
\hline 0.005 & 0.005 & 0.004 & 0.001 \\
\hline$(0.004)$ & $(0.004)$ & $(0.004)$ & $(0.001)$ \\
\hline 0.001 & 0.001 & -0.000 & -0.000 \\
\hline$(0.002)$ & $(0.002)$ & $(0.002)$ & $(0.001)$ \\
\hline 0.002 & 0.002 & 0.002 & -0.000 \\
\hline$(0.001)$ & $(0.001)$ & $(0.001)$ & $(0.001)$ \\
\hline-0.002 & -0.002 & -0.003 & 0.001 \\
\hline$(0.003)$ & $(0.003)$ & $(0.003)$ & $(0.001)$ \\
\hline 0.002 & 0.002 & 0.002 & 0.002 \\
\hline$(0.003)$ & $(0.004)$ & $(0.004)$ & $(0.003)$ \\
\hline 0.002 & 0.002 & 0.002 & 0.001 \\
\hline$(0.002)$ & $(0.002)$ & $(0.002)$ & $(0.001)$ \\
\hline-0.003 & -0.003 & -0.004 & -0.002 \\
\hline$(0.003)$ & $(0.003)$ & $(0.003)$ & $(0.002)$ \\
\hline-0.000 & 0.000 & 0.001 & 0.001 \\
\hline$(0.002)$ & $(0.001)$ & $(0.002)$ & $(0.002)$ \\
\hline 0.001 & 0.001 & 0.000 & 0.001 \\
\hline$(0.002)$ & $(0.002)$ & $(0.002)$ & $(0.001)$ \\
\hline
\end{tabular}

$-0.000$

$(0.002)$

0.000

(0.002)

0.001

(0.002)

(0.002)

$-0.002$

(0.002)

$-0.002$

(0.003)

0.003

(0.003)

$-0.001$

(0.002)

$-0.003$

$(0.003)$

$-0.005^{*}$

$(0.003)$

0.004

(0.004)

$-0.009$

(0.008)

0.005

(0.004)

$-0.001$

(0.002)

0.004

(0.003)

$-0.003$

(0.004)

0.000
$-0.001$

(0.001)

$-0.002$

(0.002)

0.003

(0.002)

0.000

(0.002)

$-0.003$

(0.003)

$-0.004 * *$

(0.002)

0.004

(0.004)

$-0.010$

(0.008)

0.006

(0.005)

$-0.000$

(0.002)

0.003

(0.003)

$-0.003$

(0.004)

0.000

$\begin{array}{cc}-0.000 & 0.001 \\ (0.002) & (0.002) \\ 0.001 & 0.001 \\ (0.002) & (0.001) \\ -0.001 & -0.002 \\ (0.001) & (0.001) \\ -0.002 & -0.003 \\ (0.003) & (0.002) \\ 0.003 & 0.003 * \\ (0.003) & (0.002) \\ -0.000 & -0.001 \\ (0.002) & (0.001) \\ -0.003 & -0.001 \\ (0.003) & (0.001) \\ -0.004 * * & -0.000 \\ (0.002) & (0.000) \\ 0.005 & 0.001 \\ (0.004) & (0.001) \\ -0.011 & -0.002 \\ (0.008) & (0.002) \\ 0.007 & -0.001 \\ (0.006) & (0.002) \\ -0.001 & -0.001 \\ (0.002) & (0.001) \\ 0.003 & 0.003 \\ (0.003) & (0.003) \\ -0.004 & -0.002 \\ (0.005) & (0.002) \\ 0.001 & -0.001\end{array}$


$(0.003) \quad(0.003) \quad(0.003) \quad(0.001)$

\begin{tabular}{lccccc}
\hline $\mathrm{R}^{2}$ (overall, incl. FE) & 0.807 & 0.814 & 0.814 & 0.824 & 0.849 \\
Log Likelihood & 2409.24 & 2489.42 & 2522.59 & 2567.47 & 3285.29 \\
Residual CD-Test & -9.858 & -9.86 & 10.71 & 11.06 & -0.94 \\
Avg. Corr. Coef. & -0.057 & -0.058 & 0.062 & 0.065 & -0.005 \\
CS-exponent $\alpha$ of & 0.50 & 0.34 & 0.76 & 0.77 & 0.73 \\
residuals [Conf. Inter] & {$[-0.07 ; 1.07]$} & {$[-1.48 ; 2.16]$} & {$[0.15 ; 1.07]$} & {$[0.44 ; 1.11]$} & {$[0.57 ; 0.90]$} \\
& & & & \\
LR-test (p-value) & & $(1)$ vs. $(2)$ & $(2)$ vs. $(3)$ & $(3)$ vs. $(4)$ & (4) vs. (5) \\
& & $<0.001$ & $<0.001$ & $<0.001$ & $<0.001$ \\
Number of Obs. & & & & \\
Number of Fed. States & 16 & 3920 & 3920 & 3904 & 3904 \\
$\mathrm{R}^{2}$ (overall, incl. FE) & 0.807 & 0.814 & 0.814 & 0.824 & 16 \\
\hline
\end{tabular}

Notes: Robust Driscoll and Kraay standard errors in parenthesis. ***p<0.01, **p<0.05, *p<0.1. Models (1) and (2) are estimated via OLS. All other models are estimated via Quasi-Maximum Likelihood. The Yu et al. (2008) biascorrection is applied in Model (4) and (5). The Stata command xsmle (Belotti et al., 2014) is used to estimate the spatial models. $\mathrm{R}^{2}$ statistics show the corrected overall $\mathrm{R}^{2}$ including the variation explained by the fixed-effects to be comparable across all five models. ${ }^{1}$ The likelihood ratio test is based on comparing the Log Likelihood between Model (3) and (4) with 2 degrees of freedom. Since this could be considered not fully adequate since the two models are estimated with a different number of observations, I redo the LR test by (i) dropping the (timewise) first observation of Model (3) such that it is also estimated with only 3904 observations and (ii) by including the observation of the last day in April, such that model (4) is estimated with 3920 observations. In both cases, Model (4) is the preferred specification. 
Table A2: Direct effects and spillover effects for intensive care patients and temperature, short-run and long-run

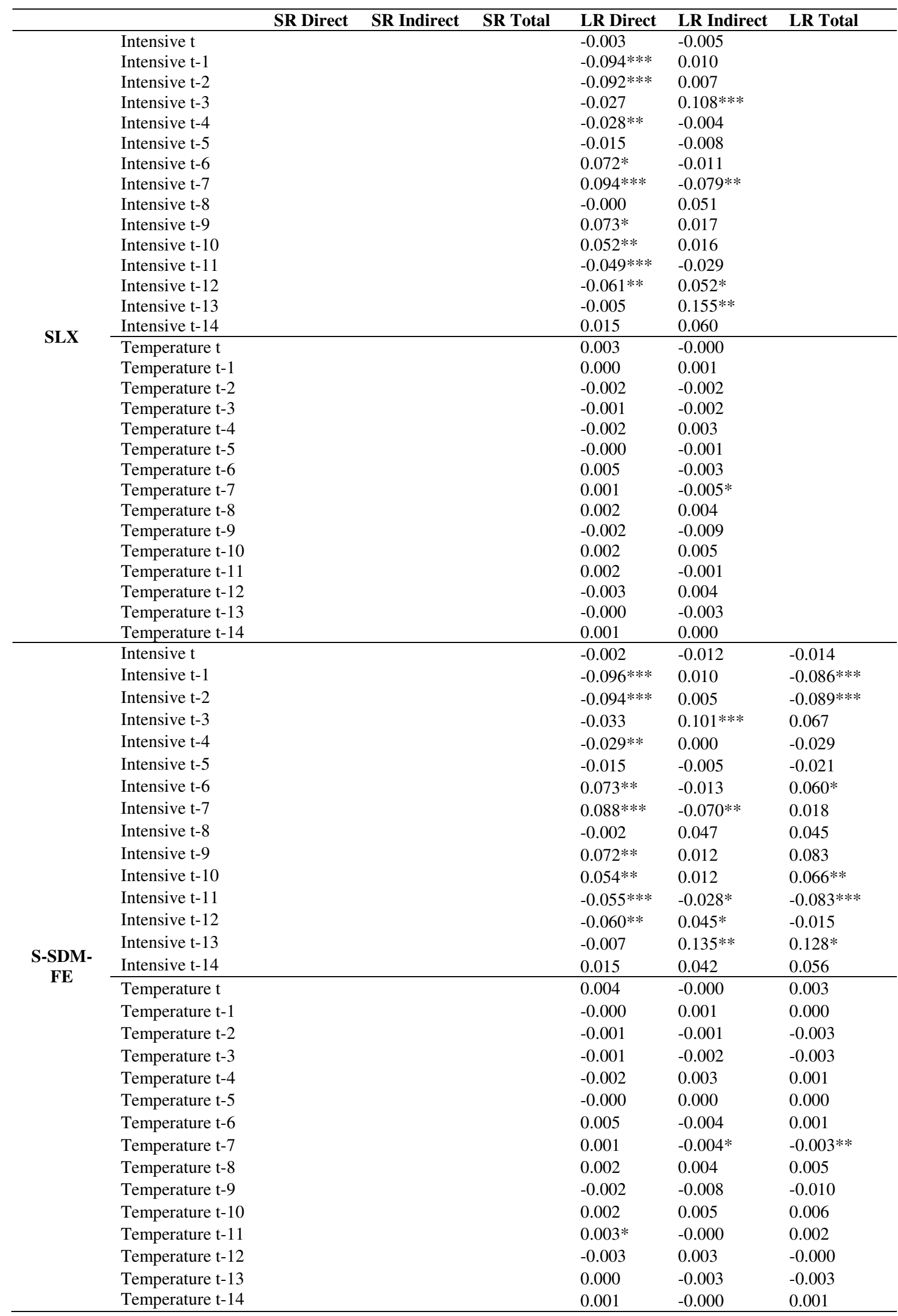




\begin{tabular}{|c|c|c|c|c|c|c|c|}
\hline \multirow{30}{*}{$\begin{array}{c}\text { D-SDM- } \\
\text { FE }\end{array}$} & Intensive $\mathrm{t}$ & 0.010 & -0.016 & -0.006 & 0.012 & -0.019 & -0.007 \\
\hline & Intensive $\mathrm{t}-1$ & $-0.092 * * *$ & 0.012 & $-0.080 * *$ & $-0.113 * * *$ & 0.017 & $-0.096 * *$ \\
\hline & Intensive $\mathrm{t}-2$ & $-0.077 * * *$ & 0.001 & $-0.075^{* * *}$ & $-0.094 * * *$ & 0.004 & $-0.090 * * *$ \\
\hline & Intensive $\mathrm{t}-3$ & -0.013 & $0.097 * * *$ & $0.085 * *$ & -0.016 & $0.117 * * *$ & $0.101 * *$ \\
\hline & Intensive $\mathrm{t}-4$ & $-0.026 *$ & -0.016 & $-0.042 *$ & $-0.032 *$ & -0.019 & $-0.051 *$ \\
\hline & Intensive t-5 & -0.013 & -0.004 & -0.016 & -0.015 & -0.004 & -0.020 \\
\hline & Intensive $\mathrm{t}-6$ & $0.073 * *$ & -0.008 & $0.065^{* *}$ & $0.089 * *$ & -0.012 & $0.078 * *$ \\
\hline & Intensive t-7 & $0.074 * *$ & $-0.065 * *$ & 0.009 & $0.091 * *$ & $-0.080 * *$ & 0.011 \\
\hline & Intensive $\mathrm{t}-8$ & -0.014 & $0.058 *$ & 0.044 & -0.017 & $0.070 *$ & 0.052 \\
\hline & Intensive t-9 & $0.075 * *$ & 0.002 & 0.077 & $0.091 * *$ & 0.000 & 0.091 \\
\hline & Intensive $\mathrm{t}-10$ & $0.043 * *$ & 0.011 & $0.054 * *$ & $0.052 * *$ & 0.012 & $0.064 * *$ \\
\hline & Intensive $\mathrm{t}-11$ & $-0.064 * * *$ & $-0.030 * *$ & $-0.094 * * *$ & $-0.078 * * *$ & $-0.035^{*}$ & $-0.112 * * *$ \\
\hline & Intensive $\mathrm{t}-12$ & $-0.050 *$ & $0.050 *$ & -0.000 & $-0.061^{*}$ & $0.061 *$ & -0.000 \\
\hline & Intensive $\mathrm{t}-13$ & 0.006 & $0.121 * *$ & 0.127 & 0.006 & $0.145^{* *}$ & 0.151 \\
\hline & Intensive $\mathrm{t}-14$ & 0.014 & 0.016 & 0.030 & 0.017 & 0.019 & 0.036 \\
\hline & Temperature $\mathrm{t}$ & 0.004 & -0.001 & 0.003 & 0.005 & -0.001 & 0.004 \\
\hline & Temperature $\mathrm{t}-1$ & -0.001 & 0.001 & 0.000 & -0.001 & 0.001 & 0.000 \\
\hline & Temperature $\mathrm{t}-2$ & -0.001 & -0.001 & -0.003 & -0.002 & -0.001 & -0.003 \\
\hline & Temperature $\mathrm{t}-3$ & -0.000 & -0.002 & -0.002 & -0.000 & -0.002 & -0.003 \\
\hline & Temperature $\mathrm{t}-4$ & -0.002 & 0.003 & 0.001 & -0.002 & 0.004 & 0.001 \\
\hline & Temperature $\mathrm{t}-5$ & 0.000 & -0.000 & -0.000 & 0.000 & -0.000 & -0.000 \\
\hline & Temperature $\mathrm{t}-6$ & 0.004 & -0.003 & 0.001 & 0.005 & -0.004 & 0.001 \\
\hline & Temperature $\mathrm{t}-7$ & 0.000 & $-0.003^{*}$ & $-0.003 * *$ & 0.000 & $-0.004 *$ & $-0.004 * *$ \\
\hline & Temperature t- 8 & 0.001 & 0.004 & 0.006 & 0.002 & 0.005 & 0.007 \\
\hline & Temperature t-9 & -0.002 & -0.009 & -0.011 & -0.002 & -0.010 & -0.013 \\
\hline & Temperature $\mathrm{t}-10$ & 0.002 & 0.006 & 0.008 & 0.002 & 0.007 & 0.009 \\
\hline & Temperature $\mathrm{t}-11$ & 0.002 & -0.001 & 0.001 & 0.003 & -0.001 & 0.001 \\
\hline & Temperature $\mathrm{t}-12$ & -0.004 & 0.003 & -0.000 & -0.004 & 0.004 & -0.001 \\
\hline & Temperature $\mathrm{t}-13$ & 0.001 & -0.003 & -0.003 & 0.001 & -0.004 & -0.003 \\
\hline & Temperature t-14 & 0.000 & 0.000 & 0.001 & 0.001 & 0.000 & 0.001 \\
\hline \multirow{30}{*}{$\begin{array}{l}\text { D-SDM- } \\
\text { CSA }\end{array}$} & Intensive $\mathrm{t}$ & -0.017 & 0.055 & 0.038 & -0.015 & 0.052 & 0.037 \\
\hline & Intensive $\mathrm{t}-1$ & $-0.068 * * *$ & $0.030 * *$ & $-0.038 * * *$ & $-0.063 * * *$ & $0.026^{*}$ & $-0.037 * * *$ \\
\hline & Intensive $\mathrm{t}-2$ & $-0.047 * * *$ & -0.013 & $-0.060 * * *$ & $-0.044 * * *$ & -0.014 & $-0.058 * * *$ \\
\hline & Intensive $\mathrm{t}-3$ & -0.003 & $0.068 * * *$ & $0.065 * * *$ & -0.002 & $0.065 * * *$ & $0.064 * * *$ \\
\hline & Intensive $\mathrm{t}-4$ & 0.001 & -0.022 & -0.021 & 0.001 & -0.022 & -0.020 \\
\hline & Intensive $\mathrm{t}-5$ & $0.020 *$ & -0.009 & 0.011 & $0.018^{*}$ & -0.008 & 0.010 \\
\hline & Intensive $\mathrm{t}-6$ & $0.039 * * *$ & 0.002 & $0.041 * *$ & $0.036^{* * *}$ & 0.004 & $0.040 * *$ \\
\hline & Intensive t-7 & $0.056 * * *$ & $-0.051 * *$ & 0.005 & $0.052 * * *$ & $-0.047 *$ & 0.005 \\
\hline & Intensive $\mathrm{t}-8$ & -0.014 & 0.020 & 0.006 & -0.013 & 0.019 & 0.006 \\
\hline & Intensive $\mathrm{t}-9$ & $0.047 * * *$ & $-0.039 * * *$ & 0.008 & $0.044 * * *$ & $-0.035 * * *$ & 0.008 \\
\hline & Intensive $\mathrm{t}-10$ & $0.061 * * *$ & $-0.058^{*}$ & 0.003 & $0.057 * * *$ & -0.054 & 0.003 \\
\hline & Intensive $\mathrm{t}-11$ & -0.003 & $-0.046 * * *$ & $-0.049 * * *$ & -0.004 & $-0.045 * * *$ & $-0.048 * * *$ \\
\hline & Intensive $\mathrm{t}-12$ & -0.021 & 0.011 & -0.010 & -0.020 & 0.010 & -0.010 \\
\hline & Intensive $\mathrm{t}-13$ & -0.014 & $0.075 * *$ & 0.061 & -0.012 & $0.072 * *$ & 0.059 \\
\hline & Intensive $\mathrm{t}-14$ & -0.003 & 0.025 & 0.021 & -0.003 & 0.024 & 0.021 \\
\hline & Temperature $\mathrm{t}$ & 0.002 & 0.001 & 0.003 & 0.002 & 0.001 & 0.003 \\
\hline & Temperature $\mathrm{t}-1$ & -0.000 & 0.001 & 0.001 & -0.000 & 0.001 & 0.001 \\
\hline & Temperature $\mathrm{t}-2$ & 0.001 & -0.002 & -0.001 & 0.001 & -0.002 & -0.001 \\
\hline & Temperature $\mathrm{t}-3$ & 0.003 & -0.003 & 0.000 & 0.003 & -0.003 & 0.000 \\
\hline & Temperature $\mathrm{t}-4$ & $-0.003 * *$ & $0.003 *$ & -0.000 & $-0.003 * *$ & $0.003 *$ & -0.000 \\
\hline & Temperature $\mathrm{t}-5$ & 0.001 & -0.001 & 0.000 & 0.001 & -0.001 & 0.000 \\
\hline & Temperature $\mathrm{t}-6$ & 0.001 & -0.001 & 0.000 & 0.001 & -0.001 & 0.000 \\
\hline & Temperature $\mathrm{t}-7$ & -0.000 & -0.000 & -0.000 & -0.000 & -0.000 & -0.000 \\
\hline & Temperature $\mathrm{t}-8$ & -0.000 & 0.001 & 0.001 & -0.000 & 0.001 & 0.001 \\
\hline & Temperature t- 9 & 0.001 & -0.002 & -0.001 & 0.001 & -0.002 & -0.001 \\
\hline & Temperature $\mathrm{t}-10$ & 0.002 & -0.001 & 0.001 & 0.002 & -0.001 & 0.001 \\
\hline & Temperature $\mathrm{t}-11$ & 0.001 & -0.001 & -0.000 & 0.001 & -0.001 & -0.000 \\
\hline & Temperature $\mathrm{t}-12$ & -0.002 & 0.003 & 0.001 & -0.002 & 0.003 & 0.001 \\
\hline & Temperature $\mathrm{t}-13$ & 0.001 & -0.001 & -0.001 & 0.001 & -0.001 & -0.001 \\
\hline & Temperature t-14 & 0.001 & -0.001 & 0.000 & 0.001 & -0.001 & 0.000 \\
\hline
\end{tabular}

Notes: Table A2 shows the marginal direct and spillover effects for the number of new intensive care patients and mean temperature, in the short-run and long-run for every spatial model from day $t$ to day $t-14$. Marginal direct (indirect) effects are derived from the mean diagonal (off-diagonal) elements of the respective model's matrix of partial derivates (LeSage and Pace, 2009; Debarsy et al., 2012; Elhorst, 2014; Elhorst, 2021). ***p<0.01, **p<0.05, *p<0.1. Standard errors are obtained via Monte Carlo Simulation as described in LeSage and Pace (2009) (see also Belotti et al., 2017, and Elhorst, 2021). SLX: Spatial lag of X model; S-SDM-FE: Static Spatial Durbin Model with time and spatial fixed effects; D-SDMFE: Dynamic Spatial Durbin Model with time and spatial fixed effects; D-SDM-CSA: Dynamic Spatial Durbin Model with Cross-Sectional Averages; SR: short-run; LR: long-run. 